\title{
Determination of surface charge properties of PC-12 cells by electrophoresis
}

\author{
Tai-Horng Young ${ }^{\mathrm{a}, *}$, Chih-Huang Hung ${ }^{\mathrm{a}}$, Shih-Wei Huang ${ }^{\mathrm{b}}$, Tien-Shing Hsieh ${ }^{\mathrm{b}}$, \\ Jyh-Ping $\mathrm{Hsu}^{\mathrm{b}}$ \\ ${ }^{a}$ Institute of Biomedical Engineering, College of Medicine and College of Engineering, National Taiwan University, Taipei, Taiwan 100, Republic of China \\ ${ }^{\mathrm{b}}$ Department of Chemical Engineering, National Taiwan University, Taipei, Taiwan 106, Republic of China
}

Received 12 May 2003; accepted 7 December 2004

Available online 11 February 2005

\begin{abstract}
The electrophoretic behavior of pheochromocytoma (PC-12) cells was investigated both experimentally and theoretically. Cell mobility in aqueous media at different $\mathrm{pHs}$ and ionic concentrations was measured, and a model, which assumed that the cell surface contains both acidic and basic functional groups, was proposed. As a result, it was revealed that the experimental data gathered can be described satisfactorily by assuming that the cell surface contains two types of monovalent acidic functional groups and one basic functional group. The values of the dissociation constants of the acidic and basic groups are found to be close to those of acidic amino acids, which indicates that the acidic amino acids may play an important role in the surface electrical properties of PC-12 cells.
\end{abstract}

(C) 2004 Elsevier Inc. All rights reserved.

Keywords: Electrophoresis; Surface charge; PC-12 cells

\section{Introduction}

Electrophoresis is an easy and rapid method used for studying the surface properties of tissue cells in vitro in which cells migrate in response to an applied electric field. On human erythrocytes, Tomita and Marchesi [1] and Heard and Seaman [2] have shown that the dissociable chemical groups that make up the cell surface charge are distributed through a significant depth normal to the cell membrane surface. Eylar et al. [3] have shown the carboxyl group of sialic acid is the main contributor to the net negative surface charge of erythrocytes at physiological $\mathrm{pH}$. In addition, a large number of studies have been carried on the electrophoretic behavior of various blood cells [4-8]. However, studies on the surface electric properties of neurons using electrophoresis technique are still limited $[9,10]$. Of course, it is likely that the effects of the $\mathrm{pH}$ and ionic strength of the extracellular

\footnotetext{
* Corresponding author. Fax: +886-2-23940049.

E-mail address: thyoung @ ha.mc.ntu.edu.tw (T.-H. Young).
}

environment on the electrophoretic behavior of other biological cells are very different from those for erythrocytes.

During the past several decades, a tremendous effort has been directed toward the development of methods for replacing lost or dysfunctional neurons following trauma or disease by means of tissue transplantation or peripheral nerve grafting [11-15]. This paper reports the surface charge properties of pheochromocytoma (PC-12) cells by measuring electrophoretic behavior in aqueous media at different $\mathrm{pHs}$ and ionic concentrations. The PC-12 cell was selected as a model cell because it could be easily detached and harvested by gently shaking the wells after a predetermined culture time. In addition, PC-12 cells resemble adrenal chromaffin cells, which share many physiological properties of neurons $[16,17]$. Beside experimental measurement, a theoretical model was proposed to simulate the electrophoretic behavior of PC-12 cells. The theoretical basis for electrophoresis was found by Smoluchowski [18], in which the relation between the electrophoretic velocity of an entity and the applied electric field was derived. The original derivation of 
Smoluchowski was based on a rigid entity with a constant surface potential in a uniform electric field. For the case of cells, the surface condition becomes more complicated, and the classic result of Smoluchowski needs to be modified accordingly [6,7,19-22]. In this study, we consider a general case where the cell surface carries dissociable functional groups and the liquid phase contains mixed electrolytes on the basis of the model proposed by Hsu et al. [21,22]. It was found that the experimental data gathered can be described satisfactorily by assuming that the cell surface contains two types of monovalent acidic functional groups and one basic functional group. The values of the dissociation constants of the acidic and basic groups are found to be close to those of acidic amino acids, which indicates that the acidic amino acids may play an important role in the surface electrical properties of $\mathrm{PC}-12$ cells.

\section{Experimental}

The rat pheochromocytoma cell line PC-12 was maintained in a supplemented RPMI-1640 medium (10\% horse serum, 5\% fetal bovine serum, penicillin G sodium 100 $\mathrm{U} / \mathrm{ml}$, streptomycin $100 \mu \mathrm{g} / \mathrm{ml}$, amphotericin B $0.25 \mu \mathrm{g} / \mathrm{ml}$ (Gibco, USA)), as recommended by Greene and Tischler [16]. The cells were maintained at $37^{\circ} \mathrm{C}$ in a humidified atmosphere of $95 \%$ air $/ 5 \% \mathrm{CO}_{2}$. Cells were passaged 1:3 once a week by detachment from the culture flask with mild agitation and a stream of fresh culture medium.

Prior to the electrophoretic mobility measurement, the ionic strength and $\mathrm{pH}$ of the cell suspension was adjusted by dilution of the cell suspension with a solution containing $\mathrm{KCl}, \mathrm{CaCl}_{2}$, and Na-acetate (pH 4-6) or Tris- $\mathrm{HCl}$ (pH 7-9). All solutions used were made isotonic by addition of glucose. The electrophoretic behavior of PC-12 cells was measured at a density of $3 \times 10^{4}$ cells $/ \mathrm{ml}$ with a Zetasizer 3000 (Malvern Instruments, UK), and the data were corrected for the viscosity and dielectric constant of the medium. All measurements were conducted at $25^{\circ} \mathrm{C}$ and their duration did not exceed $15 \mathrm{~min}$, to avoid any appreciable damage on cells. Each reported mobility is expressed as mean \pm SEM (standard error of mean) from four to six independent experiments.

\section{Results and discussion}

Fig. 1 shows the electrophoretic mobility of PC-12 cells (denoted by circle symbols) as a function of the $\mathrm{pH}$ of the medium at $2.5 \mathrm{mM} \mathrm{KCl}$ and $2 \mathrm{mM} \mathrm{CaCl}_{2}$. With deceasing $\mathrm{pH}$ of the medium, the mobility of PC- 12 cells gradually approaches zero from the negative value at $\mathrm{pH} 9$ and reverses sign at around $\mathrm{pH} 4.5$, indicating the existence of the isoelectric point for PC-12 cells. This is because the ionization of the acidic groups on the cell surface is suppressed when the $\mathrm{pH}$ of the medium is decreased. On the other hand, if the $\mathrm{pH}$

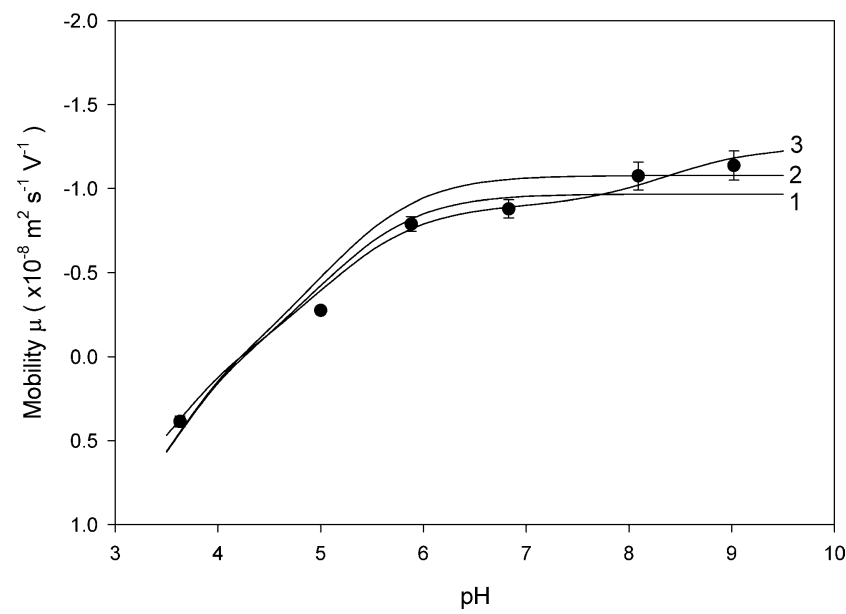

Fig. 1. Electrophoretic mobility of PC-12 cells at different $\mathrm{pH}$ values at $2.5 \mathrm{mM} \mathrm{KCl}$ and $2 \mathrm{mM} \mathrm{CaCl}_{2}$. Symbols are experimental data. Solid curves are theoretical calculations for the case where the cell surface contains two types of monovalent acidic functional groups and one type of basic functional group at ionic strength $8.5 \mathrm{mM}, \xi=0.615$. Curve 1 , $N_{\mathrm{sa} 1}=2.4 \times 10^{-8} \mathrm{~mol} / \mathrm{m}^{2} ;$ curve $2, N_{\mathrm{sa} 1}=2.7 \times 10^{-8} \mathrm{~mol} / \mathrm{m}^{2}$. Parameters used are $N_{\mathrm{sa} 2}=1.2 \times 10^{-8} \mathrm{~mol} / \mathrm{m}^{2}, N_{\mathrm{sb}}=7.0 \times 10^{-8} \mathrm{~mol} / \mathrm{m}^{2}$, $K_{\mathrm{sa} 1}=1.0 \times 10^{-5} \mathrm{M}, K_{\mathrm{sa} 2}=0 \mathrm{M}, K_{\mathrm{b}}=1.0 \times 10^{-3} \mathrm{M}$. Curve 3, $N_{\mathrm{sa} 1}=2.7 \times 10^{-8} \mathrm{~mol} / \mathrm{m}^{2}, K_{\mathrm{c} 1}=10 \mathrm{~m}^{5} / \mathrm{mol}^{2}, K_{\mathrm{c} 2}=10 \mathrm{~m}^{5} / \mathrm{mol}^{2} . \mathrm{Pa}-$ rameters used are $N_{\mathrm{sa} 2}=1.2 \times 10^{-8} \mathrm{~mol} / \mathrm{m}^{2}, N_{\mathrm{sb}}=7.0 \times 10^{-8} \mathrm{~mol} / \mathrm{m}^{2}$, $K_{\mathrm{sa} 1}=1.0 \times 10^{-5} \mathrm{M}, K_{\mathrm{sa} 2}=7.0 \times 10^{-9} \mathrm{M}, K_{\mathrm{b}}=1.0 \times 10^{-3} \mathrm{M}$, $K_{\mathrm{c} 1}=10 \mathrm{~m}^{5} / \mathrm{mol}^{2}, K_{\mathrm{c} 2}=10 \mathrm{~m}^{5} / \mathrm{mol}^{2}$.

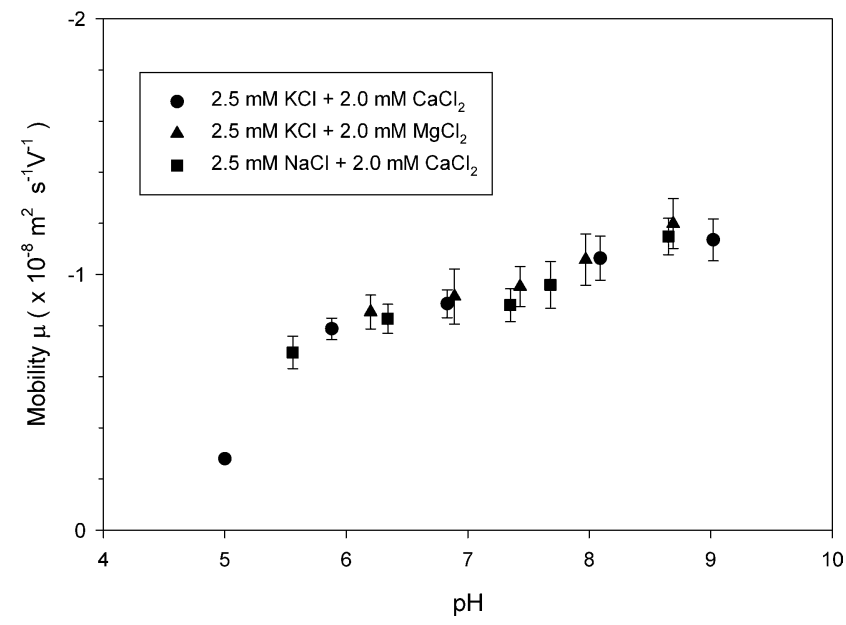

Fig. 2. Electrophoretic mobility of $\mathrm{PC}-12$ cells at various $\mathrm{pH}$ values for three kinds of mixed electrolyte solutions: $(\bullet) \mathrm{KCl}+\mathrm{CaCl}_{2},(\mathbf{\Lambda}) \mathrm{KCl}+\mathrm{MgCl}_{2}$,

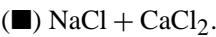

is sufficiently low, the positive charges arise from the protonated basic groups on the cell surface. Therefore, it becomes possible that the net charge of the surfaces of PC-12 cells changes its sign, which leads to PC-12 cells having positive mobility.

The electrophoretic mobility of PC-12 cells as a function of $\mathrm{pH}$ of the medium for different kinds of mixed electrolyte solutions is shown in Fig. 2. Very similar results are obtained for different kinds of mixed electrolyte solutions. This implies that the presence of different ions affects the cell sur- 


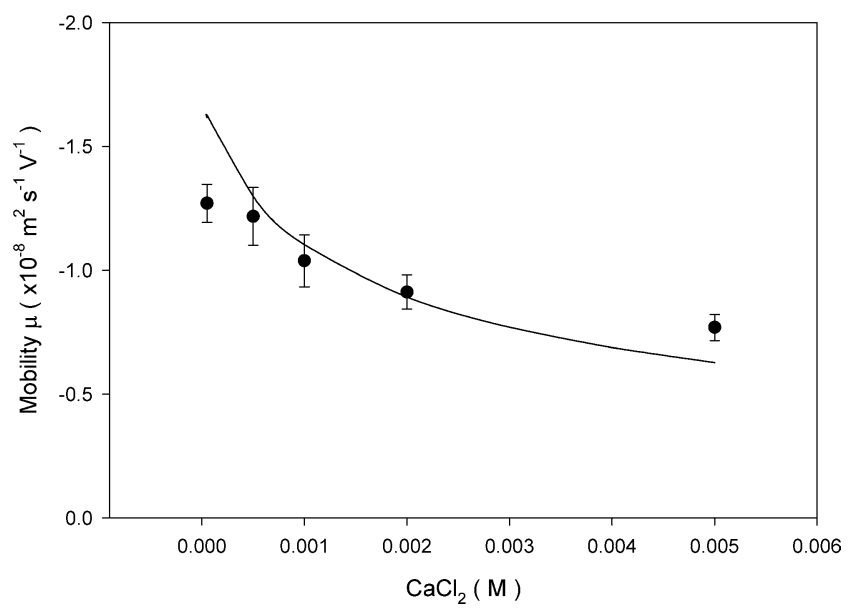

Fig. 3. Electrophoretic mobility of $\mathrm{PC}-12$ cells at various $\mathrm{CaCl}_{2}$ concentrations. Each solution contained Tris- $\mathrm{HCl}(\mathrm{pH} 7.4), 2.5 \mathrm{mM} \mathrm{KCl}$, and the corresponding quantity of glucose. Symbols are experimental data. The solid curve is the simulated result based on present model. Parameters used are $N_{\mathrm{sa} 1}=2.7 \times 10^{-8} \mathrm{~mol} / \mathrm{m}^{2}, N_{\mathrm{sa} 2}=1.2 \times 10^{-8} \mathrm{~mol} / \mathrm{m}^{2}$, $N_{\mathrm{sb}}=7.0 \times 10^{-8} \mathrm{~mol} / \mathrm{m}^{2}, K_{\mathrm{sa} 1}=1.0 \times 10^{-5} \mathrm{M}, K_{\mathrm{sa} 2}=7.0 \times 10^{-9} \mathrm{M}$, $K_{\mathrm{b}}=1.0 \times 10^{-3} \mathrm{M}, K_{\mathrm{c} 1}=10 \mathrm{~m}^{5} / \mathrm{mol}^{2}, K_{\mathrm{c} 2}=10 \mathrm{~m}^{5} / \mathrm{mol}^{2}$.

face little during the measurement of their electrophoretic mobility.

Fig. 3 shows the electrophoretic mobility of PC-12 cells (denoted by circle symbols) as a function of the concentration of $\mathrm{Ca}^{2+}$. Each solution contains Tris- $\mathrm{HCl}(\mathrm{pH}$ 7.4), $2.5 \mathrm{mM} \mathrm{KCl}$, and the corresponding quantity of glucose. The mobility of PC-12 cells decreases in absolute value as the concentration of $\mathrm{Ca}^{2+}$ increases, indicating the screening effect of electrolytes on the negative charges of the cell surface.

A theoretical model is proposed to describe the electrophoretic data of PC-12 cells gathered in the experiment. Previously, Hsu et al. have proposed a theoretical model [10] for the description of the electrophoretic behavior of cerebellar granule neurons in a medium containing a mixed $(a: b)+(c: b)$ electrolyte, $a$ and $c$ being the valences of cations and $b$ the valence of anions. This model assumed that the fixed charge on the cell surface arises mainly from the dissociation of a monovalent acidic functional group, and that the $\mathrm{Ca}^{2+}$ in the medium is allowed to combine with dissociated functional groups [23]. In this study, the model of Hsu et al. [10] is modified by cell surface containing two monovalent acidic functional groups, $\mathrm{HA}_{\mathrm{I}}$ and $\mathrm{HA}_{\mathrm{II}}$, and a basic functional group, B. The dissociation-association reactions of these functional groups can be expressed as

$\mathrm{HA}_{\mathrm{I}} \rightleftarrows \mathrm{H}^{+}+\mathrm{A}_{\mathrm{I}}^{-}$,

$\mathrm{HA}_{\mathrm{II}} \rightleftarrows \mathrm{H}^{+}+\mathrm{A}_{\mathrm{II}}^{-}$,

$\mathrm{BH}^{+} \rightleftarrows \mathrm{H}^{+}+\mathrm{B}$.

Let $K_{\mathrm{sa} 1}=C_{\mathrm{H}^{+}} C_{\mathrm{A}_{\mathrm{I}}^{-}} / C_{\mathrm{HA}_{\mathrm{I}}}$ and $K_{\mathrm{sa} 2}=C_{\mathrm{H}^{+}} C_{\mathrm{A}_{\mathrm{II}}^{-}} / \mathrm{C}_{\mathrm{HA}_{\mathrm{II}}}$ be the equilibrium constants for Eqs. (1) and (2), and $K_{\mathrm{b}}=$
$C_{\mathrm{H}^{+}} C_{\mathrm{B}} / C_{\mathrm{BH}^{+}}$be the equilibrium constant for Eq. (3). Suppose that this divalent cation is capable of binding to $\mathrm{A}_{\mathrm{I}}^{-}$and $\mathrm{A}_{\mathrm{II}}^{-}$through the following expressions:

$2 \mathrm{~A}_{\mathrm{I}}^{-}+\mathrm{M}^{2+} \rightleftarrows \mathrm{MA}_{\mathrm{I} 2}$,

$2 \mathrm{~A}_{\mathrm{II}}^{-}+\mathrm{M}^{2+} \rightleftarrows \mathrm{MA}_{\mathrm{II} 2}$.

Let $K_{\mathrm{c} 1}=C_{\mathrm{MA}_{\mathrm{I} 2}} / C_{\mathrm{M}^{2+}}\left(C_{\mathrm{A}_{\mathrm{I}}^{-}}\right)^{2}$ and $K_{\mathrm{c} 2}=C_{\mathrm{MA}_{\mathrm{II} 2}} / C_{\mathrm{M}^{2+}} \times$ $\left(C_{\mathrm{A}_{\text {II }}^{-}}\right)^{2}$ be the equilibrium constants for Eqs. (4) and (5). If we assume that the spatial variation in the concentration of $\mathrm{H}^{+}$and $\mathrm{M}^{2+}$ follows the Boltzmann distribution, then

$C_{\mathrm{H}^{+}}=C_{\mathrm{H}^{+}}^{0} \exp (-\varphi)$,

$C_{\mathrm{M}^{2+}}=C_{\mathrm{M}^{2+}}^{0} \exp (-2 \varphi)$,

where $C_{\mathrm{H}^{+}}^{0}$ and $C_{\mathrm{M}^{2+}}^{0}$ are the bulk concentration of $\mathrm{H}^{+}$and $\mathrm{M}^{2+}$ and $\varphi$ is the scaled electrical potential.

If we let $N_{\mathrm{sa} 1}, N_{\mathrm{sa} 2}$, and $N_{\mathrm{sb}}$ be the surface concentrations of $\mathrm{HA}_{\mathrm{I}}, \mathrm{HA}_{\mathrm{II}}$, and $\mathrm{HB}$, respectively, then

$N_{\mathrm{sa} 1}=C_{\mathrm{HA}_{\mathrm{I}}}+C_{\mathrm{A}_{\mathrm{I}}^{-}}+C_{\mathrm{MA}_{\mathrm{I} 2}}$,

$N_{\mathrm{sa} 2}=C_{\mathrm{HA}_{\mathrm{II}}}+C_{\mathrm{A}_{\mathrm{II}}^{-}}+C_{\mathrm{MA}_{\mathrm{II} 2}}$,

$N_{\mathrm{sb}}=C_{\mathrm{BH}^{+}}+C_{\mathrm{B}}$.

The surface concentration, $C_{\mathrm{A}_{\mathrm{I}}^{-}}, C_{\mathrm{A}_{I I}^{-}}$, and $C_{\mathrm{BH}^{+}}$, can be expressed as [10]

$C_{\mathrm{A}_{\mathrm{I}}^{-}}=\frac{\sqrt{y_{1}^{2}+4 K_{\mathrm{c} 1} C_{\mathrm{M}^{2+}} N_{\mathrm{sa} 1}}-y_{1}}{2 K_{\mathrm{c} 1} C_{\mathrm{M}^{2+}}}$,

$C_{\mathrm{A}_{\mathrm{II}}^{-}}=\frac{\sqrt{y_{2}^{2}+4 K_{\mathrm{c} 2} C_{\mathrm{M}^{2+}} N_{\mathrm{sa} 2}}-y_{2}}{2 K_{\mathrm{c} 2} C_{\mathrm{M}^{2+}}}$,

$C_{\mathrm{BH}^{+}}=\frac{N_{\mathrm{sb}}}{1+K_{\mathrm{b}} / C_{\mathrm{H}^{+}}}$,

where $y_{1}=1+C_{\mathrm{H}^{+}} / K_{\mathrm{sa} 1}$ and $y_{2}=1+C_{\mathrm{H}^{+}} / K_{\mathrm{sa} 2}$.

The surface charge density can be expressed as

$\sigma=F\left(C_{\mathrm{BH}^{+}}-C_{\mathrm{A}_{\mathrm{I}}^{-}}-C_{\mathrm{A}_{\mathrm{II}}^{-}}\right)$,

where $F$ is the Faraday constant.

The electrophoretic mobility of cell under consideration involves solving simultaneously the equations describing the electrical field and the flow field. Here, we assume that the linear size of a cell is much larger than the thickness of the electric double layer surrounding it, and the applied electric field $E$ is parallel to cell surface. The spatial variation of the electrical potential can be described by the PoissonBoltzmann equation,

$\frac{d^{2} \varphi}{d X^{2}}=\frac{\left[e^{b \varphi}-(1-\xi) e^{-a \varphi}-\xi e^{-c \varphi}\right]}{(a+b)+(c-a) \xi}$, 
where the scaled variables are defined by $\varphi=e \phi / k_{\mathrm{B}} T$, $X=\kappa r, \xi=c n_{c}^{0} / b n_{b}^{0}, \kappa^{2}=e^{2}\left[a(a+b) n_{a}^{0}+c(b+c) n_{c}^{0}\right] /$ $\varepsilon_{0} \varepsilon_{\mathrm{r}} k_{\mathrm{B}} T$, and $b n_{b}^{0}=a n_{a}^{0}+c n_{c}^{0}, \varphi$ and $X$ being respectively the scaled electrical potential and the scaled distance from the cell surface. $\phi$ is the electrical potential, $\xi$ is the fraction of cations of valence $c$ in the bulk liquid phase, $n_{a}^{0}, n_{b}^{0}$, and $n_{c}^{0}$ are, respectively, the number concentrations of ionic species of valences $a,-b$, and $c$ in the bulk liquid phase, $e$ is the elementary charge, $\varepsilon_{\mathrm{r}}$ and $\varepsilon_{0}$ are, respectively, the relative permittivity of the liquid phase and the permittivity of a vacuum, $k_{\mathrm{B}}$ and $T$ denote, respectively, the Boltzmann constant and the absolute temperature, and $\kappa$ and $r$ are, respectively, the reciprocal Debye length and the distance from the cell surface.

The boundary conditions associated with Eq. (15) are assumed as

$\frac{d \varphi}{d X}=\Gamma \quad$ as $X \rightarrow 0$,

$\varphi=0 \quad$ and $\quad \frac{d \varphi}{d X}=0 \quad$ as $X \rightarrow \infty$,

where $\Gamma=-e \sigma / \varepsilon_{0} \varepsilon_{\mathrm{r}} k_{\mathrm{B}} T \kappa$ is the scaled surface charge density with $\sigma$ evaluated from Eq. (14). Here, we assume that both the electrical potential and its gradient vanish at a point far away from the cell surface.

The flow field can be described by the scaled NavierStokes equation [24],

$\frac{d^{2} U}{d X^{2}}=L \frac{e^{b \varphi}-(1-\xi) e^{-a \varphi}-\xi e^{-c \varphi}}{(a+b)+(c-a) \xi}$,

where the scaled variables are defined by $U=u / U_{0}$ and $L=\varepsilon_{0} \varepsilon_{\mathrm{r}} R T E / \eta F U_{0}, u$ and $U_{0}$ being respectively the magnitudes of the velocities of the liquid phase near and far away from a cell, $U$ and $E$ being respectively the magnitude of the scaled velocity and the strength of the applied electric field, and $\eta$ being the viscosity of the liquid phase. For convenience, the cell is held fixed at steady state, and the liquid moves in the inverse direction as that of cell. Therefore, the boundary conditions associated with Eq. (18) are

$U=0 \quad$ at $X=0$,

$U \rightarrow-1 \quad$ as $X \rightarrow \infty$.

The governing equations, Eqs. (15) and (18), and the associated boundary conditions, Eqs. (16), (17), (19), and (20), are solved by a finite difference method based on a central difference scheme for the case $a=1, b=1, c=2$, $T=298 \mathrm{~K}, \varepsilon_{\mathrm{r}}=78.5$, and $E=1000 \mathrm{~V} / \mathrm{m}$. The results obtained are then used to calculate the electrophoretic mobility of a cell, $\mu=U_{0} / E$.

Both the experimental data for the electrophoretic mobility of a cell $\mu$ as a function of $\mathrm{pH}$ and the theoretical results based on Eqs. (15)-(20) are presented in Fig. 1. For the cases of curves 1 and $2,|\mu|$ increases with $\mathrm{pH}$ for $5<\mathrm{pH}<7$, but remains roughly constant if $\mathrm{pH}$ exceeds 7 . For $\mathrm{pH}>5$, the $|\mu|$ in curve 2 is larger than that in curve 1 , which is expected because a larger $N_{\text {sal }}$ leads to a higher surface charge density. While the experimental data are better described by curve 1 for $\mathrm{pH}<7$, curve 2 becomes the better choice if $\mathrm{pH}>7$. Since $K_{\mathrm{sa} 2}$ is assumed to be zero for the cases of curves 1 and 2, it is insufficient to fit the experimental data for assuming only one type of acidic functional group (i.e., $\mathrm{HA}_{\mathrm{I}}$ ) is present on cell surface. Assuming the presence of the second type of acidic functional group can alleviate this problem. As illustrated in curve 3, if $K_{\mathrm{sa} 2} \neq 0,|\mu|$ keeps on increasing even if $\mathrm{pH}$ is higher than 7. Apparently, the continuous increase in mobility arises from the dissociation of the second $\mathrm{H}^{+}$in the acidic functional group (i.e., $\mathrm{HA}_{\mathrm{II}}$ ), leading to a more negatively charged surface, and the higher the $\mathrm{pH}$, the more complete the degree of dissociation. The estimated values for the equilibrium constants $K_{\mathrm{sa} 1}, K_{\mathrm{sa} 2}$, and $K_{\mathrm{b}}$ for the case of curve 3 are $1.0 \times 10^{-5}, 7.0 \times 10^{-9}$, and $1.0 \times 10^{-3} \mathrm{M}$, respectively. It is interesting to note that these equilibrium constants are very close to the $\mathrm{p} K$ values of acidic amino acids. For example, the $\mathrm{p} K$ values of glutamate are $2.19,4.25$, and 9.67. This suggests that the acidic amino acid may play an important role in the surface charge properties of PC-12 cells. However, it does not exclude the possibility that other weak acids may contribute to the electrophoretic behavior of PC-12 cells. Similar to erythrocytes [3], it is likely that the carboxylic-acid-containing groups are involved in the surface charge of PC-12 cells, which needs further evidence from biochemical studies.

In order to check the validity of the assumption that the surface charge of PC-12 cells can be appropriately described by the present model, the theoretical electrophoretic mobility of PC-12 cells was calculated at different concentrations of $\mathrm{Ca}^{2+}$, using the same parameters for the case of curve 3 of Fig. 1. As seen in Fig. 3, the present model is capable of describing the influence of the concentration of $\mathrm{Ca}^{2+}$ on the mobility of cells in general. A slight deviation between theoretical values and experimental data is observed at the lower and the higher concentrations of $\mathrm{Ca}^{2+}$, which may arise from the parameters used in the calculations being based on the concentration of $\mathrm{CaCl}_{2}$ being $2 \mathrm{mM}$. However, both the theoretical curve and the experimental data points show the screening effect of electrolytes on the surface charges of PC-12 cells; i.e., the mobility of PC-12 cells decreases as the concentration of $\mathrm{Ca}^{2+}$ increases. In addition, good agreement with experimental results can be obtained as the concentrations of $\mathrm{Ca}^{2+}$ are between 0.5 and $2 \mathrm{mM}$. Therefore, the present model, although not optimum, is still applicable to the prediction of the electrophoretic behavior of PC-12 cells at different concentrations of $\mathrm{Ca}^{2+}$.

In summary, the charged conditions on cell surface are of complicated nature. Here, we assume that the surface charge on cell surface arises from the dissociation of two types of monovalent acidic functional groups and one basic functional group. A theoretical model based on this assumption was found to be capable of describing the electrophoretic behavior of PC-12 cells for $\mathrm{pH}$ ranging from 3.5 to 9 , and the 
influence of the concentration of $\mathrm{Ca}^{2+}$. The present model, while simple in its structure, can serve as a useful research tool for the analysis of the surface properties of cells.

\section{Acknowledgment}

This work is supported by the National Science Council of the Republic of China.

\section{References}

[1] M. Tomita, V.T. Marchesi, Proc. Natl. Acad. Sci. USA 72 (1975) 2964-2968.

[2] D.M. Heard, G.V.F. Seaman, J. Gen. Physiol. 42 (1960) 203-220.

[3] E.H. Eylar, M.A. Madoff, O.V. Brody, J.L. Oncley, J. Biol. Chem. 237 (1962) 1992-2000.

[4] D.A. Haydon, G.V.F. Seaman, Arch. Biochem. Biophys. 122 (1967) 126-135.

[5] G.V.F. Seaman, D.H. Heard, J. Gen. Physiol. 44 (1960) 251-268.

[6] S. Levine, S. Levine, K.A. Sharp, D.E. Brooks, Biophys. J. 42 (1983) 127-135.

[7] S. Kawahata, H. Ohshima, N. Muramatsu, T. Kondo, J. Colloid Interface Sci. 138 (1990) 182-186.

[8] K. Morita, N. Muramatsu, H. Ohshima, T. Kondo, J. Colloid Interface Sci. 147 (1991) 457-461.
[9] S.L. Mironov, E.V. Dolgaya, J. Membr. Biol. 86 (1985) 107-202.

[10] J.P. Hsu, S.W. Huang, T.S. Hsieh, T.H. Young, W.W. Hu, Electrophoresis 23 (2002) 2001-2006.

[11] E. Yavin, Z. Yavin, J. Cell Biol. 62 (1974) 540-546.

[12] S.T. Carbonetto, M.M. Gruver, D.C. Turner, Science 216 (1982) $897-$ 899.

[13] P. Aebischer, R.F. Valentini, P. Dario, C. Domenici, P.M. Galletti, Brain Res. 436 (1987) 165-168.

[14] F. Langone, S. Lora, F.M. Veronese, P. Caliceti, P.P. Parnigotto, F. Valenti, G. Palma, Biomaterials 16 (1995) 347-353.

[15] M.S. Shoichet, S.R. Winn, S. Athavale, J.M. Harris, F.T. Gentile, Biotech. Bioeng. 43 (1994) 563-572.

[16] L.A. Greene, A.S. Tischler, Proc. Natl. Acad. Sci. USA 73 (1976) 2424-2428.

[17] Y. Shoji-Kasai, A. Yoshida, K. Sato, T. Hoshino, A. Ogura, S. Kondo, Y. Fujimoto, R. Kuwahara, R. Kato, M. Takahashi, Science 256 (1992) 1820-1823.

[18] R.G. Hunter, Foundations of Colloid Science, vol. 1, Oxford Univ. Press, Oxford, 1989.

[19] H. Ohshima, T. Kondo, J. Colloid Interface Sci. 116 (1987) 305-311.

[20] K. Makino, F. Fukai, T. Kawaguchi, H. Ohshima, Colloids Surf. B 5 (1995) 221-226.

[21] J.P. Hsu, Y.C. Kuo, J. Colloid Interface Sci. 183 (1996) 194-198.

[22] J.P. Hsu, T.S. Hsieh, T.H. Young, S. Tseng, Electrophoresis 24 (2003) 1338-1346.

[23] G.V. Seaman, P.S. Vassar, M.J. Kendall, Arch. Biochem. Biophys. 135 (1969) 356-362.

[24] R.B. Bird, W.E. Stewart, E.N. Ligthtfoot, Transport Phenomena, Oxford Univ. Press, New York, 1960. 